INGURUAK [71] | 2021 | 37-55

http://dx.doi.org/10.18543/inguruak-71-2021-art03

ISSN 0214-7912

\title{
Sobre las teorías de la nación
}

\section{About nation theories}

\author{
Javier Antón Merino* \\ Universidad de Burgos
}

RESUMEN: El estudio de las teorías de la nación acarrea considerables dificultades por la multitud de enfoques, tanto en términos conceptuales como explicativos. La inexistencia de una teoría unificada provoca que conceptos básicos como nación y gran parte de sus derivados sean términos en disputa, lo que genera serios impedimentos a la hora de fijarlos y ofrecer definiciones claras y ampliamente compartidas por la academia.

En este artículo, partiendo de la definición weberiana de Estado, se efectuará una revisión y clasificación sistemática de los principales enfoques y aportaciones teóricas de la nación, proponiendo un marco a partir del cual se podrán ubicar a los autores más autorizados sobre la materia, así como a sus propuestas. Además, también se expondrán las diferentes tipologías desarrollas entorno al termino nacionalismo. Todo ello, tiene por objetivo sintetizar, ordenar y clarificar los distintos enfoques teóricos en un tema de estudio cuya relevancia y vigencia continúa estando de lo más presente en la actualidad.

Palabras clave: primordialismo, constructivismo, modernismo, perennialismo y etnosimbolismo.

ABSTRACT: Studying the theories of nations entails considerable difficulties when observing the heterogeneous approaches related to its ideas and explanations. As a result of the lack of a unified theory, concepts such as nation, and a majority of its derived nouns, are what the academia consider as unsettled terms.

This article, taking as the starting point the Webber definition of State, will carry out a review and systematic classification of those considered to be the main approaches and theoretical contributions about nation, suggesting a framework through which the most relevant authors on nation studies can be placed. Along with this, nationalism term typologies will be expounded with the main objective of summarizing, structure and clarify the diverse theoretical approaches of a study subject, that continues to be relevant and in effect up to this day.

Keywords: primordialism, constructivism, modernism, perennialism and ethno-symbolism.

* Correspondencia a/Correspondence to: Javier Antón Merino. Universidad de Burgos - Javieram@ubu.es - https://orcid.org/0000-0002-7915-1121 Cómo citar/How to cite: Antón Merino, Javier (2021). «Sobre las teorías de la nación»; Inguruak, 71, 37-55. (http://dx.doi.org/10.18543/inguruak-71-2021-art03). Recibido/Received: 1 octubre 2021; Versión final/Final version: 3 diciembre 2021. ISSN 0214-7912 / (c) 2021 UPV/EHU

(c) (7) Esta obra está bajo una Licencia

Creative Commons Atribución-NoComercial-SinDerivadas 4.0 Internacional 


\section{INTRODUCCIÓN}

Probablemente una de las definiciones más repetidas en Ciencia Política es la definición weberiana de Estado. Para Max Weber, el Estado es una «comunidad humana que reivindica con éxito el monopolio del uso legítimo de la fuerza física dentro de un territorio determinado» (Weber, 1948, p. 78). Posteriormente esta definición ha sido desarrollada por otros autores. Así, en la actualidad, se entiende por Estado el «conjunto de instituciones y medios de control y de coerción, que tiene por objeto crear y mantener la cohesión interna de las unidades políticas y permitirles ejercer su acción en el exterior» (Schnapper, 2001, p. 36).

Los Estados modernos pueden ser plurinacionales o Estados-nación. El Estado-nación unitario es fruto de la modernidad y se da «cuando la unidad política territorial coincide con el asentamiento territorial de un grupo nacional único o mayoritario» (Moreno, 2008, p. 29), mientras que el Estado plurinacional es aquel Estado en el que coexisten más de una nación y dónde las culturas más pequeñas conforman «minorías nacionales» ${ }^{1}$ (Kymlicka, 1996, p. 26).

Pero ¿Qué es una nación? Resulta más que pertinente para el presente escrito retomar esta pregunta lanzada por Ernest Renan en su célebre conferencia en la Sorbona hace más de un siglo (Renan, 1887). Renan planteó esta pregunta sumergido en un debate dialéctico con pensadores alemanes como Heinrich Von Treitschke (1916), David Friedrich Strauss y Theodor Mommsen (2010 [1871]) con motivo de la disputa franco-prusiana de los territorios de Alsacia y Lorena (Rivero, 2016). Y es que, desde los debates pioneros en torno a la idea de nacionalidad protagonizados por Lord Acton (1907 [1862]) y John Stuart Mill ${ }^{2}$ (1861) (Rivero, 2011, 2017), hasta los autores más contemporáneos, la palabra nación y gran parte de la terminología derivada de este concepto han sido términos controvertidos y que no han generado consenso dentro de la academia.

Para Weber, la idea de nación pertenece a la esfera de los valores y se refiere al sentimiento específico de solidaridad de ciertos grupos de individuos frente a otros (Weber, 1968, p. 922). Además este autor considera que las naciones se manifiestan de forma adecuada en Estados propios, por lo que cada nación tiende a producir su correspondiente Estado (Weber, 1948, p. 176). Más allá de esta consideración weberiana, en la actualidad, existen una gran variedad de enfoques, teorías y autores que han reflexionado sobre la nación, lo que convierte a este término, y gran parte de sus derivados, en conceptos en disputa dentro de la disciplina. Esta multitud de enfoques y definiciones resulta una barrera

\footnotetext{
${ }^{1}$ En este sentido, Alfred Stepan (2001) propone el cumplimiento de dos requisitos básicos para que un país pueda ser considerado plurinacional, por un lado, «debe tener identidades lingüísticas delimitadas territorialmente que se compaginen con etnias y/o religiones y/o identidades culturales» y, además, dentro de su territorio deben existir «destacados grupos políticos con la pretensión de construir soberanías políticas, o un Estado o Estados independientes, en torno a estas diferencias territoriales» (Stepan, 2001, p. 327).

${ }^{2}$ Sobre la concepción de nación, nacionalismo y nacionalidad en el pensamiento de John Stuart Mill véase el estudio de Georgios Varouxakis (2002).
} 
difícil de superar a la hora de afrontar estudios empíricos sobre este tema y por ello, este artículo se propone realizar una revisión sistemática de los principales autores y teorías sobre la nación. Proponiendo con ello una taxonomía para ubicar a los autores dentro de los principales enfoques de este campo de estudio. En la primera parte del artículo se realizará una revisión de la literatura más autorizada sobre las teorías de la nación, clasificando a los autores en sus respectivos enfoques. Posteriormente, se resumirán las distintas tipologías de nacionalismo. Y, por último, el articulo finalizará con unas breves conclusiones.

\section{LAS TEORÍAS MÁS RELEVANTES EN EL ESTUDIO DE LA NACIÓN}

En cuanto al término nación, a pesar de que las definiciones son ampliamente heterogéneas, se puede hablar de dos corrientes teóricas principales: la primordialista y la constructivista. Estas dos corrientes difieren enormemente en lo que se refiere al origen de la nación y al concepto y el origen del nacionalismo.

El primordialismo es una corriente académica muy minoritaria, que defiende que el origen de las naciones es natural e inmemorable, que está ligado al surgimiento de las primeras sociedades humanas tratándose de una realidad dada. La nación, por lo tanto, es atemporal y consustancial a la propia humanidad y ha pervivido a través de los años prácticamente sin cambios (Marcos-Marné, 2015; Moreno Almendral, 2016; Smith, 2000, 2004). Dentro de la corriente primordialista, existe una vertiente sociobiológica, donde cabe destacar el trabajo de Pierre Van den Berghe (1978) y una vertiente cultural, asociada a la obra del sociólogo estadounidense Edward Shils (1957) y del antropólogo del mismo país Clifford Geertz (1986 [1973]).

Por otra parte, el constructivismo es la corriente académica mayoritaria y parte de la idea de que las naciones son un producto social que fue creado y «construido» en un momento histórico determinado. Dentro de esta corriente académica se pueden diferenciar los paradigmas modernistas, perennialistas y etnosimbolistas (Smith, 2000).

El modernismo es el paradigma dominante. Los estudiosos afines al modernismo consideran que las naciones, los Estados-nación y el nacionalismo son construcciones sociales productos de la modernidad, derivados de los desarrollos económicos (Hechter, 1976, 2000, 2001; Nairn, 1990), políticos (Breuilly, 1990 [1982]; Giddens, 1985; Hobsbawm, 2000 [1990], 2002 [1983]), ideológicos (Berlin, 1992 [1979]; Kedourie, 1988 [1960]) y/o socioculturales (B. Anderson, 2006 [1983]; Gellner, 1988 [1983], 1995, 1997) de la época moderna.

Uno de los primeros autores modernistas fue Elie Kedourie. Kedourie estaba especialmente interesado en el concepto de nacionalismo, al que define como «una doctrina in- 
ventada en Europa al comienzo del siglo XIX» (Kedourie, 1988 [1960], p. 1) que "pretende suministrar un criterio para determinar la unidad de población adecuada para disponer de un gobierno exclusivamente propio, para el ejercicio legítimo del poder en el Estado y para la organización justa de la sociedad internacional» (Kedourie, 1988 [1960], p. 1). Kedourie parte de una distinción entre política constitucional e ideología. La política constitucional, según este autor, consiste en la gestión pacífica de los conflictos de una sociedad determinada, mientras que las ideologías, son hijas de la Revolución Francesa y proponen la creación de programas racionales para resolver las grandes cuestiones políticas. Kedourie, crítico con la política ideológica, considera al nacionalismo como una de las creaciones más importantes de este tipo. Según este autor, el nacionalismo se caracteriza por dar por supuesto lo siguiente: la división natural de la humanidad en naciones; la existencia de características que determinan la distinción de esas naciones y la consideración de que el mejor tipo de gobierno es el autogobierno nacional. Kedourie opina que el nacionalismo triunfó como ideología en el momento en que la mayoría de las naciones aceptaron el «principio de las nacionalidades ${ }^{3}$ ». Principio que tendría su antecedente en la idea kantiana de autonomía moral, que posteriormente desarrollaron autores románticos alemanes como Johann Gottfried Herder y Johann Gottlieb Fitchte hasta configurar la actual autodeterminación nacional (Kedourie, 1988 [1960]).

De acuerdo con Rivero (2017), es Ernest Gellner el autor más crítico con la conexión que estableció Kedourie entre la obra de Immanuel Kant y el nacionalismo. Gellner define el nacionalismo como «un principio político», inherentemente moderno, "que sostiene que debe haber congruencia entre la unidad nacional y la política» (Gellner, 1988 [1983], p. 13). Para este autor, el nacionalismo es un producto de la modernidad y la comunión entre nación y Estado es contingente, ya que históricamente no ha sido una necesidad universal. Los Estados nacieron antes que las naciones, por lo que la aparición de estas ha sido muchas veces independiente a la de los propios Estados y viceversa. De hecho, Gellner argumenta que la homogeneidad cultural no ha sido determinante en la creación de fronteras políticas hasta después de la Revolución Industrial. Además, la industrialización trajo consigo una generalización de la «alta cultura» ${ }^{4}$ entre el conjunto de la sociedad. Estas dos premisas explicarían la vinculación entre el nacionalismo y el mundo moderno, ya que la homogeneidad y omnipresencia cultural no se habrían tenido en cuenta y no habrían sido determinantes en la creación de Estados hasta épocas muy recientes. Por último, una de las ideas más relevantes de este autor es que el nacionalismo tiene la capacidad de engendrar naciones y no al revés (Gellner, 1988 [1983], p. 80). Para Gellner, las naciones son una necesidad producto de un cambio estructural que ha generado la modernidad y el nacionalismo resucita, modifica e inventa unidades culturales que a través de un proceso de centralización, generalización y homogeneización cultural dan lugar a las naciones modernas (Gellner, 1988 [1983], 1995, 1997).

\footnotetext{
${ }^{3}$ Sobre el principio de las nacionalidades véase Giusseppe Mazzini (2004 [1846-1847]).

${ }^{4}$ Por alta cultura Gellner entiende la alfabetización, competencias técnicas y educación formal propiamente dichas.
} 
La obra de John Breuilly representa una aproximación en clave política al paradigma modernista. Breuilly define nacionalismo como el término que «se utiliza para referirnos a movimientos que tratan de obtener o ejercer el poder del Estado, y que justifican tales acciones con argumentos nacionalistas» (Breuilly, 1990 [1982], p. 13). Siendo los argumentos nacionalistas «una doctrina política construida sobre tres afirmaciones básicas: existe una nación con un carácter explícito y peculiar; los intereses y valores de esa nación tienen prioridad sobre todos los demás intereses y valores; y la nación tiene que ser tan independiente como sea posible. Habitualmente, esto exige al menos la obtención de la soberanía política» (Breuilly, 1990 [1982], p. 13). Para Breuilly, tanto la nación como el nacionalismo son fenómenos políticos modernos, en los que el papel de las élites políticas para concebirlos ha sido crucial (Breuilly, 1990 [1982], p. 51).

En la versión socioeconómica del paradigma modernista destacan los trabajos de Tom Nairn (1990) y Michael Hechter (1976, 2000, 2001). Las teorías de Nairn y Hechter parten de la idea central del desarrollo espacial desigual del capitalismo. Según estos autores, el mundo y los países quedan divididos en regiones que se sitúan en el centro o la periferia económica. El nacionalismo surge del encuentro desigual entre el centro desarrollado y la periferia subdesarrollada ${ }^{5}$. Nairn propone una teoría que se acomoda a las exigencias occidentales de nacionalismos como es el caso del nacionalismo escocés. Para Nairn, las élites de las regiones periféricas reaccionan contra las imposiciones del centro e intentan hacer valer sus intereses. Para deshacerse de las cadenas imperialistas, estas élites necesitan del apoyo de las clases populares, que son captadas con la apelación a defender una identidad, cultura, etnia o lengua común frente a las fuerzas externas de dominación. Para este autor, el nacionalismo es una creación de la modernidad que inevitablemente posee dos caras, como el Dios romano Jano, una de ellas conservadora que mira hacia un pasado mítico, la tradición y elementos étnicos que sirven de cemento social; mientras que la otra es progresista y mira hacia un futuro de desarrollo, modernización y libertad (Nairn, 1990, p. 18). Por su parte, Hechter tomando como ejemplo la periferia celta de Reino Unido -Escocia, Irlanda del Norte y Gales-, habla de colonialismo interior. Para Hechter, la dominación del centro sobre la periferia no es solo política sino que también se basa en una explotación económica derivada de una división cultural del trabajo que contribuye al desarrollo del nacionalismo (Hechter, 1976).

También desde la tradición marxista se han defendido posturas modernistas. Más allá de los primeros debates sobre la relación entre el nacionalismo y el marxismo que enfrentaron a Lenin (1914) y a Rosa Luxemburgo (1976), Benedict Anderson (2006 [1983]) y Eric Hobsbawm (2000 [1990], 2002 [1983]) son considerados los pensadores marxistas con aportaciones más relevantes en el campo de la nación.

\footnotetext{
5 Tanto Nairn como Hechter están fuertemente influidos por el contexto imperial británico. En este sentido, varios estudios han tratado el vínculo existente entre imperialismo y nacionalismo. Sobre la relación entre estos conceptos véase John Hobson (1902), Hannah Arendt (1982 [1951]), Antonio Annino (2011) y Josep María Fradera (2015).
} 
Para Anderson, el nacionalismo es un sistema cultural vinculado a la propagación de un artefacto cultural llamado nación, originado en el siglo xviII y propio de la edad contemporánea. Anderson entiende a la nación como un artefacto cultural, dado que, para él la nación es una comunidad política imaginaria e imaginada, a la vez que inherentemente limitada y soberana (B. Anderson, 2006 [1983], p. 23). Este autor, califica a la nación de comunidad imaginada, porque a pesar de que la mayoría de sus miembros no se conocen personalmente, existen entre ellos las imágenes, la camaradería y los rasgos emocionales propios de una comunidad. La nación es «inherentemente limitada» porque la comunidad no abarca a la humanidad, sino que define un criterio de pertenecía y exclusión. Por último, es soberana porque como respuesta a las ideas de la Revolución Francesa aspira a erguirse como un Estado soberano. Para Anderson, la aparición de la imprenta y la difusión de la prensa escrita tuvo un efecto clave para generar sentimiento de pertenecía a estas «comunidades imaginadas» (B. Anderson, 2006 [1983], pp. 96-101). Este efecto lo ejemplifica con la emancipación de los Estados de América. Anderson considera que la nación fue concebida en América mucho antes que en la mayor parte de Europa (B. Anderson, 2006 [1983], pp. 81). En la emancipación política de los estados americanos tuvieron un papel clave las figuras de los funcionarios criollos y de los impresores criollos provinciales. Los funcionarios criollos eran trabajadores que cambiaban de residencia y viajaban por las unidades administrativas del imperio según iban ascendiendo laboralmente. Los «peregrinos criollos» tenían unas fuertes restricciones para ascender por el simple hecho de haber nacido en América. Estos funcionarios, una vez que eran asignados a la capital de la unidad administrativa imperial en la que se encontraban, carecían de movilidad vertical y tenían constreñidos sus movimientos laterales (a otras unidades administrativas imperiales). Por lo que, según Anderson, «el accidente del nacimiento en las Américas los condenaba a la subordinación, aunque en términos de lengua, religión, ascendencia o maneras fuesen en gran medida indistinguibles del español peninsular» (B. Anderson, 2006 [1983], pp. 91-92). Por su parte, los impresores criollos provinciales nacieron una vez el capitalismo impreso llego a la América española, y mediante el uso de la imprenta y la difusión de periódicos fueron fundamentales para crear comunidades imaginadas entre un conjunto de lectores. Estas dos figuras son para Anderson los determinantes de la emancipación de las colonias hispanas en América.

Por su parte, Hobsbawm entiende que las naciones son un producto del nacionalismo, una creación resultado de la «invención de tradiciones» y la ingeniería social. Este autor distingue entre dos tipos de nacionalismo: el nacionalismo político de masas y el nacionalismo etnolingüístico. El nacionalismo político de masas está vinculado a la Revolución Francesa y fue común en Europa entre 1830 y 1870. Esta clase de nacionalismo opera con el principio de umbral, por el que solo las naciones con un territorio y una población suficientemente grandes como para mantener una gran economía de mercado capitalista tenían el derecho de auto-determinarse ${ }^{6}$. Hobsbawm valora de forma positiva el nacionalismo po-

${ }^{6}$ El principio de umbral ha sido defendido por influyentes ideólogos del principio de las nacionalidades como Giusseppe Mazzini (2004 [1846-1847]). 
lítico de masas, ya que según su opinión favorece el cambio social. El otro tipo de nacionalismo es el que este autor denomina etnolingüístico. El nacionalismo etnolingüístico es propio del periodo de tiempo comprendido entre 1870 y 1914, ha vuelto a la escena política a partir de los años setenta, e incide en el derecho a separarse sobre la base de la existencia de vínculos de carácter étnico o lingüístico, alejándose del principio de umbral y acercándose hacia la derecha política. Hobsbawm critica el nacionalismo etnolingüístico por considerarlo reaccionario y excluyente, y vaticina su inminente desaparición. Para Hobsbawm, el nacionalismo ya no constituye ni uno de los vectores determinantes del desarrollo histórico ni un programa político global. La etnicidad y la lengua han dejado de ser una guía para el futuro y a pesar de que las naciones y el nacionalismo seguirán presentes en la historia, estos solo se desarrollaran de manera subordinada y desempeñaran un papel secundario en el panorama político global (Hobsbawm, 2000 [1990], p. 201).

Por último, también partiendo de una perspectiva modernista, pero centrando su análisis en otros aspectos, se encuentra la original obra de Michael Billig (2014 [1995]). Billig, desde un enfoque cercano a la psicología social, focaliza su atención en los elementos del nacionalismo que se expresan en la vida cotidiana, están fuertemente arraigados y son tan rutinarios que pasan desapercibidos o son invisibles para la mayoría de los ciudadanos. Para ello, este autor introduce el concepto de «nacionalismo banal», que se refiere a todo aquello inserto en la sociedad que es nacionalista, aunque la mayoría de la ciudadanía no sea consciente de ello. Banderas en edificios oficiales, agrupaciones nacionales de competiciones deportivas, el uso del lenguaje, la prensa nacional, las monedas y billetes, el mapa del tiempo y un largo etcétera, no se perciben como nacionalismo explícito, pero son ejemplos de elementos insertos en el día a día que sirven para recordar a las personas de forma continuada su identidad nacional, socializarlas en los valores nacionales y reproducir a las naciones (Billig, 2014 [1995], pp. 20-25). Estos elementos completamente normalizados, no resultan problemáticos para otros autores, por lo que en general los teóricos de la nación han tendido a estudiar la identidad nacional como algo pasional y exacerbado, pero esta, también tiene un componente «banal», ordinario o común, que impregna diariamente la vida cotidiana y que es el centro de la teoría de Billig (2014 [1995]).

El paradigma perennialista coincide con el modernista en que las naciones no tienen un origen natural y no son inherentes a la condición humana, pero considera que su génesis es anterior a la modernidad. Para los autores perennialistas las naciones son entidades de larga existencia y el concepto nación es menos restrictivo que el de los modernistas. Dentro de este paradigma destacan los trabajos de Walker Connor (1994), Adrian Hastings (2000), Conor Cruise O’Brian (1999), Anthony W. Marx (2003) y Liah Greenfeld (2005 [1992]).

El trabajo de Walker Connor ${ }^{7}$ denuncia la gran confusión terminológica existente en lo que se refiere a los conceptos clave del estudio de la nación y el nacionalismo. Para este

\footnotetext{
7 Con respecto al pensamiento de Walker Connor, además de las lecturas del propio autor, véase también el libro editado por Daniele Conversi (2002) sobre su obra.
} 
autor, las palabras nación y Estado, así como nacionalismo y patriotismo, se usan normalmente como sinónimos sin serlo. Por ello en su obra realiza un gran esfuerzo de clarificación y precisión terminológica. Connor entiende por nación «un grupo de gente que siente que comparte una relación ancestral». Siendo este grupo el «más extenso que puede exigir lealtad a una persona, porque existen vínculos de parentesco que se sienten como tales» (Connor, 1994, p. 288). La nación es moderna en un sentido cronológico, pero está fuertemente ligada a la etnia. De hecho, la nación no es más que una forma evolucionada del grupo étnico, una etnia auto-diferenciada, auto-definida y auto-consciente donde la población ha adquirido una conciencia nacional. En la idea de nación de este autor prima un elemento psicológico y la nación se basa en lazos de parentesco ancestrales sentidos, donde el mito de origen no suele tener relación alguna con las líneas de descendencia reales. Connor considera el patriotismo como la lealtad hacia el propio Estado, el propio país y sus instituciones, mientras que entiende el nacionalismo como el sentimiento de amor hacia la propia nación, un vínculo psicológico surgido de los sentimientos de parentesco que va más allá de la racionalidad (Connor, 1994, p. 206). Según Connor, el nacionalismo como una manifestación de la etnicidad politizada solo puede ser predicado étnicamente (Connor 1994).

Adrian Hasting y Conor Cruise O’Brian analizan la influencia de las religiones en el desarrollo del nacionalismo. Para estos autores, existe un nacionalismo o proto-nacionalismo muy vinculado a la religión cristiana desde la Baja Edad Media (Hastings, 2000; O’Brian, 1988). Desde el siglo xi, Hastings observa un precoz Estado-nación con una religión común, una lengua vernácula, administración propia y un territorio compacto en Inglaterra, y de forma menos evidente en otros países de Europa Occidental como Francia ${ }^{8}$. Según Hastings, la nación y el nacionalismo son «característicamente cristianos y, siempre que han aparecido en otras culturas lo han hecho dentro de un proceso de occidentalización y de imitación del mundo cristiano» (Hastings, 2000, p. 230). De esta afirmación habría que excluir al pueblo judío, puesto que fue el que aportó al mundo el modelo original de nacionalidad, así como el ejemplo de lo que suponía ser una nación ${ }^{9}$. Para Hastings, el cristianismo ha modelado la construcción nacional mediante siete modos fundamentales: la configuración y canonización de los orígenes o santificación del punto de partida nacional; la mitologización de las amenazas contra la identidad nacional; el papel social del clero como educadores, traductores de textos y mediadores entre las identidades de gobernantes y gobernados; la producción de textos escritos en lengua vernácula; la provisión de un modelo bíblico para la nación fomentando por el Nuevo Testamento; el desarrollo de iglesias nacionales auto-cefálicas dentro de la tradición ortodoxa y protestante; y el descubrimiento de un destino nacional único (Hastings, 2000). Además, O’Brien subraya la importancia de la Revolución Francesa como la primera revolución secular de

\footnotetext{
${ }^{8}$ Estos dos casos, son también para otros autores perennialistas, como el británico Hugh Seton-Watson (1977), los modelos paradigmáticos de naciones antiguas y continuas en Europa.

${ }^{9}$ Desarrollando esta misma línea, argumentando la existencia de un nacionalismo premoderno y explorando los lazos entre el antiguo pueblo judío y el moderno Estado de Israel, es pertinente destacar la obra de Aviel Roshwald (2006).
} 
la historia, siendo un momento histórico clave en la separación entre el nacionalismo y la religión (O’Brian, 1988).

Anthony W. Marx sitúa el nacimiento del nacionalismo en Francia e Inglaterra en el siglo xvi y subraya la importancia que tuvo la religión en la construcción de sociedades homogéneas con una fuerte lealtad de masas, cohesión popular interna y un poder del Estado sólido. Sociedades que por sus características eran propicias para la creación de Estados-nación y el desarrollo del nacionalismo entendido como «un principio político de solidaridad popular creado con el propósito de coincidir con el Estado» (Marx, 2003, p. 8). Anthony W. Marx subraya que el surgimiento de las naciones y los Estados no debe confundirse, pero que, sin embargo, ambos están muy ligados (Marx, 2003, p. 6). Por otra parte, para este autor las tensiones y conflictos religiosos fueron fundamentales a la hora de excluir estratégicamente a determinados grupos para homogeneizar socialmente a la población y solidificar la lealtad nacional, llevando a cabo un proceso de «cohesión excluyente». La religión, además de ser una creencia, ejercía como un mecanismo de solidaridad primaria básica que servía de cemento social y podía actuar como germen del nacionalismo. Por ello, excluir, estigmatizar y eliminar al «otro» interno por motivos religiosos, así como luchar contra enemigos externos por los mismos motivos - guerras religiosaspasaron a ser requisitos ineludibles para la cohesión interna de los países y el inicio del nacionalismo (Marx, 2003, pp. 21-29). Posteriormente, la amnesia selectiva de las naciones ha borrado el lenguaje, los motivos y disputas religiosas que inspiraron inicialmente los ideales de unidad y formación nacional, dejando al nacionalismo cívico y liberal como artífice de las independencias y creaciones nacionales y democráticas. El nacionalismo y la democracia son para Anthony W. Marx pensamientos relativamente inclusivos pero que necesitan de un periodo previo de conflictividad y exclusión — religiosa o social—, esencial para la unidad y consolidación nacional, y necesario para una futura democracia (Marx, 2003, pp. 29-31).

Por otra parte, Liah Greenfeld (2005 [1992]) desarrolla una teoría muy particular que sitúa la génesis de la idea moderna de la nación en Inglaterra a comienzos del siglo xvi. Esta idea será exportada y extendida a partir del siglo xviII. Para Greenfeld, se debe interpretar a la nación como un elemento constitutivo de la modernidad, y la modernidad se define a partir del nacionalismo (Greenfeld, 2005 [1992], p. 22), ya que la aparición de la primera nación dio comienzo a la «era del nacionalismo». Esta autora define al nacionalismo como una forma de conciencia que «sitúa la fuente de la identidad individual dentro de un «pueblo» que se considera depositario de la soberanía, objeto central de la lealtad y fundamento de la solidaridad colectiva» (Greenfeld, 2005 [1992], p. 1).

El último paradigma constructivista es el paradigma etnosimbolista. El etnosimbolismo representa una alternativa que combina atributos de los otros enfoques. Este paradigma, a pesar de no negar la importancia de la modernidad para entender el desarrollo contemporáneo del nacionalismo, centra su estudio en los elementos subjetivos - memoria, símbolos, mitos...-, alejándose de una observación exclusivamente orientada a las élites y 
llevando a cabo un análisis con un enfoque cronológico de larga duración -longue durée- de las pautas sociales y culturales. Para los etnosimbolistas, los conceptos de etnia y etnicidad como identidades colectivas pre-modernas, tienen un papel central a la hora de explicar el surgimiento de las naciones modernas, ya que estos son fenómenos que hunden sus raíces en épocas anteriores a la modernidad. Entre los autores principales afines a este paradigma destacan la obra de John Armstrong (1982), John Hutchinson $(1987,1994)$ y el prolífico trabajo de Anthony Smith (1996, 1997, 2000, 2004).

Anthony Smith parte del concepto de nacionalismo, entendido este como el «movimiento ideológico pensado para la obtención y el mantenimiento del autogobierno y la independencia de un grupo, algunos de cuyos miembros creen que constituyen una nación real o potencial» (Smith, 2000, p. 330), para retroceder hasta las primeras manifestaciones de sentimientos culturales colectivos. Las comunidades étnicas representan estas manifestaciones, Smith define a las comunidades étnicas como «las poblaciones humanas dotadas de nombre que comparten mitos sagrados sobre los ancestros, historias y culturas, mantienen una asociación con un territorio específico y un sentido de la solidaridad» (Smith, 2000, p. 336). Para Smith, la mayoría de las naciones tienen un núcleo o unos antecedentes étnicos, por lo que los términos "etnia» y "nación» forman parte de un continuum que conecta las antiguas culturas con las naciones modernas y en el que, aunque las formas que han adoptado las etnias han ido transformándose con la historia, las percepciones persistentes del grupo nacional tienen un origen premoderno y étnico. Smith entiende por nación «una población humana que comparte un territorio histórico, mitos y recuerdos, una cultura pública de masas, una economía y derechos y deberes comunes para todos sus miembros» (Smith, 1996, p. 359). Para este autor, la etnia se sitúa en el corazón de las propias naciones, y las naciones no son más que sociedades abstractas que aspiran a prolongar el sistema mítico-simbólico de las etnias precedentes. Las etnias premodernas no son naciones, pero abastecen a estas con una serie de mitos, símbolos, valores, costumbres y tradiciones distintivas, así como de memorias compartidas que son necesarias para la creación de una base nacional sólida. Smith distingue entre etnias laterales, que priman los vínculos horizontales y tienen tendencia a la formación de élites, y etnias verticales, más cohesionadas, cerradas e identificadas con un territorio. Smith concluye que las naciones modernas están estrechamente conectadas con las antiguas categorías étnicas, puesto que la memoria colectiva es un componente esencial en la creación y reproducción de las naciones (Smith, 1996, 1997, 2000, 2004).

Tras revisar la literatura más autorizada sobre las teorías de la nación, la tabla 1 recoge un resumen de la taxonomía realizada durante este primer apartado. En ella, se clasifican los principales autores de la materia dentro de los grandes enfoques teóricos mencionados con anterioridad. En este sentido, queda patente la distinción entre las corrientes teóricas primordialista y constructivista y dentro de esta última, la distinción entre modernistas, perennialistas y etnosimbolistas, así como la adscripción de los principales autores a su corriente teórica correspondiente. 
Tabla 1. Teorías de la nación: enfoques y autores

\begin{tabular}{|c|l|l|l|}
\hline \multicolumn{2}{|c|}{ Primordialistas } & \multicolumn{2}{c|}{$\begin{array}{c}\text { P. Van den Berghe } \\
\text { Clifford Geertz } \\
\text { Edward Shils }\end{array}$} \\
\hline \multirow{5}{*}{ Constructivistas } & \multirow{3}{*}{ Modernistas } & $\begin{array}{l}\text { E. Kedourie } \\
\text { E. Gellner } \\
\text { E. Hobsbawm } \\
\text { T. Nairn }\end{array}$ & $\begin{array}{l}\text { I. Berlin } \\
\text { B. Anderson } \\
\text { J. Breuilly } \\
\text { M. Hechter }\end{array}$ \\
\cline { 3 - 5 } & Perennialistas & $\begin{array}{l}\text { W. Connor } \\
\text { A. Hastings } \\
\text { C. O’Brian } \\
\text { L. Greeenfeld }\end{array}$ & $\begin{array}{l}\text { A. W. Marx } \\
\text { A. Roshwald } \\
\text { H. Seton-Watson }\end{array}$ \\
\cline { 2 - 4 } & Etnosimbolistas & $\begin{array}{l}\text { J. Armstrong } \\
\text { J. Hutchinson } \\
\text { A. Smith }\end{array}$ \\
\hline
\end{tabular}

Fuente: elaboración propia.

\section{MÁS ALLÁ DE LA TAXONOMÍA}

Una vez clasificados los distintos enfoques teóricos de la nación y las principales aportaciones de los autores más autorizados en la materia, se va a proceder a exponer distintas tipologías de nacionalismo que han servido para llevar a cabo estudios eminentemente empíricos sobre esta temática. Así, atendiendo a quién constituye la nación y cuál es la base de la legitimidad de las exigencias nacionalistas, en una primera tipología se puede distinguir entre los tipos ideales de nacionalismo étnico y cívico (Clua i Faine, 2011; Fusi, 2003; Greenfeld, 2005 [1992]; Keating, 1996; Kymlicka, 1996; Núñez Seixas 2019; Smith, 1997, 2000, 2004; Taguieff \& Delannoi, 1993).

El tipo ideal de nacionalismo étnico es aquel que sostiene que las naciones están constituidas por grupos étnicos y «la pertenencia a la comunidad nacional se confiere basándose en criterios atribuibles. A su vez, la nación es la base de los derechos, las libertades y las obligaciones del individuo» (Keating, 1996, p. 14). El nacionalismo étnico se vincula con el concepto de nación cultural — kulturnation — de Friedrich Meinecke (1970) y con la tradición de la concepción alemana de nación representada por el pensamiento de autores como Theodor Mommsen o Johann Gottfried Herder. Así, se entiende a las naciones como comunidades con orígenes étnicos comunes y lazos de linaje o sangre, por lo que la pertenencia a una nación es objetiva y adscriptiva, viene dada por el nacimiento y no caben las decisiones voluntarias e individuales.

Por otra parte, el tipo ideal de nacionalismo cívico presenta al nacionalismo como

una empresa colectiva de sus miembros, pero tiene sus raíces en la aquiescencia individual antes que en la identidad atribuible. Se basa en valores e instituciones en 
común, y en pautas de interacción social. Los portadores de identidad nacional son instituciones, costumbres, recuerdos históricos y valores racionales/seculares. Cualquiera puede entrar a formar parte de la nación con independencia de su cuna o de sus orígenes étnicos, aunque el coste de adaptación varía. (Keating, 1996, p. 16)

Este tipo de nacionalismo está ligado al concepto de nación política —Staatsnation- de Friedrich Meinecke (1970), así como a la histórica concepción francesa de nación ${ }^{10}$, definida por Ernest Renan como «una gran solidaridad, constituida por el sentimiento de los sacrificios que se han hecho y los sacrificios que todavía se está dispuesto a hacer» (Renan 1887, p. 307) y cuyos principios residen en la idea del «plebiscito cotidiano». Los criterios de pertenecía en el nacionalismo cívico son abiertos y voluntarios y están ligados al territorio y la ciudadanía.

Como se ha especificado con anterioridad, los tipos de nacionalismo cívico y étnico son tipos ideales que se rigen por principios antagónicos que representan una diferenciación analítica y normativa. En realidad, todos los movimientos nacionalistas existentes tienen elementos y características cívicas y étnicas con diferentes grados de mezcla.

Atendiendo a un criterio territorial surge una segunda tipología que diferencia entre nacionalismo estatal, mayoritario o de nación con Estado — state nationalism - y nacionalismo periférico, minoritario o de nación sin Estado — stateless nationalism - (Díez Medrano, 1999; Guibernau, 1996, 2013; Keating, 1996, 2008; Linz, 2008; Lipset \& Rokkan, 1967; Moreno, 2008).

El nacionalismo estatal, mayoritario o de nación con Estado — state nationalism - es aquel nacionalismo que se da «cuando nación y Estado se solapan o cuando la prevalencia de una nación en un Estado de carácter plural conlleva la asimilación de los grupos étnicos minoritarios» (Moreno, 2008, p. 28). Mientras que los nacionalismos periféricos, minoritarios o de naciones sin Estado — stateless nationalism - «suponen la negación de las reivindicaciones exclusivas por parte del nacionalismo estatal y la afirmación de los derechos nacionales de autodeterminación para los grupos incluidos en él» (Keating, 1996, p. 31). El nacionalismo periférico aparece habitualmente en territorios geográficamente alejados de la capital administrativa de los Estados plurinacionales, pudiendo ser resultado de una mala integración en los procesos de construcción estatal, y reivindica una definición de nación alternativa y que compite con la propuesta por el Estado. Este tipo de nacionalismo es una fuente de conflictos entre el Estado y la periferia, así como en el interior del territorio al que los nacionalistas periféricos dicen representar. Por ello algunos autores, para referirse a las naciones periféricas con grandes movimientos nacionalistas y una fuerte división interior entre los nacionalistas periféricos y los nacionalistas estatales, hablan del concepto de «naciones divididas» (Díez Medrano, 1999; Linz, 1985).

${ }^{10}$ La literatura académica ha tendido a idealizar la concepción francesa de nación. Los autores franceses del siglo xix, partían de la premisa de que la nación francesa se encontraba en la cúspide de la civilización y por ello, era su responsabilidad asumir un rol de liderazgo mundial (Michelet, 2005). 
El nacionalismo periférico, a su vez, puede ser secesionista o buscar una construcción nacional dentro de un Estado anfitrión. Se entiende por nacionalismo secesionista la clase de nacionalismo periférico cuyo objetivo es «el establecimiento de un nuevo Estado soberano en una parte del territorio de un Estado existente» (Buchanan, 2013, p. 14). Cabe recordar, que el nacionalismo periférico tiene pretensiones negociables y cambiantes a lo largo del tiempo. Los nacionalismos periféricos pueden perseguir llegar a diferentes tipos de acuerdos políticos de autodeterminación ${ }^{11}$ para acomodar su situación dentro de un Estado anfitrión. Este tipo de nacionalismo solo es secesionista si tiene por objetivo final la «retirada formal de una parte de un Estado consolidado y reconocido internacionalmente dando lugar a la creación de un nuevo Estado» (L. Anderson, 2007, p. 188).

\section{CONCLUSIONES}

En 1979, Isaiah Berlin en el último capítulo de su libro Contra la corriente: ensayos sobre historia de las ideas mostraba su sorpresa por el hecho de que ninguno de los grandes teóricos políticos del siglo xix hubiese sido capaz de predecir la importancia que iba a tener el nacionalismo en el transcurso del siglo xx. En este texto, Berlin, argumentaba cómo el nacionalismo fue considerado erróneamente por liberales, conservadores y marxistas como una ideología pasajera que desaparecería una vez eliminadas las causas de su creación (Berlin, 1992 [1979], pp. 419-420). Más tarde, en 1990, el célebre historiador Eric Hobsbawm publicó su famoso libro Naciones y nacionalismo desde 1780, donde, en sus últimas páginas, argumentaba la pérdida de importancia de esta ideología en el mundo actual y se atrevía a vaticinar que a pesar de la futura presencia del nacionalismo en la sociedad, su tiempo histórico ya había concluido, por lo que en el futuro su papel iba a ser cada vez más insignificante (Hobsbawm, 2000 [1990], pp. 201-202). El final del siglo xx y las dos primeras décadas del siglo xxi, parecen haber desmentido la predicción del historiador británico, mostrando una vez más la gran capacidad de resiliencia de la ideología nacionalista. Y es que las postrimerías del siglo pasado y los albores del siglo xxi han sido testigos del crecimiento de diferentes formas de nacionalismo a lo largo y ancho del planeta, lo cual ha promovido un aumento del interés académico y el número de publicaciones y estudio que versan sobre este tema.

Por ello, resulta cuando menos sorprendente, no ya la inexistencia de una teoría unificada sobre este fenómeno, sino la ausencia de un consenso académico mínimo en la definición de los conceptos básicos relacionados con el estudio de la nación y el nacionalismo. En este artículo, sin aspirar a elaborar una historia conceptual exhaustiva sobre la idea de la nación, se ha desarrollado un trabajo de sinterización, clarificación y clasificación sistemá-

${ }^{11}$ Existe una confusión generalizada entre los términos secesión y autodeterminación. La autodeterminación política puede lograrse mediante un número muy amplio de acuerdos en los que se pueden alcanzar distintos grados y formas de independencia política. La secesión es la forma más extrema de autodeterminación, por lo que la autodeterminación es un concepto más amplio que entre sus formas contiene a la secesión (Buchanan 2013; Moreno y Lecours 2009). 
tica de los distintos enfoques teóricos de la nación, realizando una taxonomía en la que se han ubicado a los más notables teóricos de este campo de estudio en sus respectivos enfoques. Además, la revisión de la literatura también ha servido para ordenar las principales tipologías de nacionalismo presentes en multitud de trabajos empíricos sobre este fenómeno. Con todo, esta aportación permite definir un marco a partir del cual se pueden ubicar las principales propuestas, teorías e ideas concernientes al estudio de la nación.

\section{REFERENCIAS BIBLIOGRÁFICAS}

Anderson, B. (2006 [1983]). Comunidades imaginadas. Reflexiones sobre el origen y la difusión del nacionalismo. México D. F: Fondo de Cultura Económica.

Anderson, L. (2007). Federalism and Secessionism: Institutional Influences on Nationalist Politics in Québec. Nationalism and Ethnic Politics, 13(2), 187-211. https://doi. org/10.1080/13537110701293070

Annino, A. (2011). Acerca de lo imperial en perspectiva comparada. Semata: Ciencias Sociais e Humanidades, 23(23), 45-60.

Arendt, H. (1982 [1951]). Los orígenes del totalitarismo. Madrid: Taurus.

Armstrong, J. (1982). Nations before nationalism. Chapel Hill: University of North Carolina Press.

Berlin, I. (1992 [1979]). Contra la corriente: ensayos sobre historia de las ideas. México D. F: Fondo de Cultura Económica.

Billig, M. (2014 [1995]). Nacionalismo Banal. Madrid: Capitán Swing.

Breuilly, J. (1990 [1982]). Nacionalismo y Estado. Barcelona: Ediciones Pomares-Corredor.

Buchanan, A. (2013). Secesión. Causas y consecuencias del divorcio político. Barcelona: Ariel.

Clua i Faine, M. (2011). Catalan , immigrants and charnegos : " race ", " cultura " and « mixture » in Catalan Nationalist Rhetoric. Revista de Antropología Social, 1, 55-75.

Connor, W. (1994). Ethnonationalism: The Quest for Understanding. Contemporary Sociology. Princeton: Princeton University Press. https://doi.org/10.2307/2077661

Conversi, D. (2003). Ethnonationalism in the Contemporary World. Londres y Nueva York: Routledge. https://doi.org/10.4324/9780203166246 
Díez Medrano, J. (1999). Naciones divididas: clase, política y nacionalismo en el País Vasco y Cataluña. Madrid: Centro de Investigaciones Sociológicas.

Emerich Edward Dalberg, J. (1907 [1862]). Nationality. En J. Neville Figgis \& R. Vere Laurence (Eds.), The History of Freedom and Other Essays (pp. 270-301). Londres: Macmillan. https://doi.org/10.1093/library/s5-XVII.3.238

Emizet, K. N., \& Hesli, V. L. (1995). The Disposition to Secede. Comparative Political Studies, 27(4), 493-536. https://doi.org/10.1177/0010414095027004002

Fradera, Josep Maria. 2015. La nación imperial: derechos, representación y ciudadanía en los imperios de Gran Bretaña, Francia, España y Estados Unidos (1750-1918). Barcelona: Edhasa.

Fusi, J. P. (2003). La patria lejana. El nacionalismo en el siglo xx. Madrid: Taurus.

Geertz, C. (1986). La interpretación de las culturas. Barcelona: Editorial Gedisa.

Gellner, E. (1988 [1983]). Naciones y Nacionalismo. Madrid: Alianza Editorial.

Gellner, E. (1995). Encuentros con el nacionalismo. Madrid: Alianza Editorial.

Gellner, E. (1997). Nacionalismo. Barcelona: Destino.

Giddens, A. (1985). The nation-state and violence. Cambridge: Polity Press.

Greenfeld, L. (2005 [1992]). Nacionalismo: cinco vías a la modernidad. Madrid: Centro de Estudios Políticos y Constitucionales.

Guibernau, M. (1996). Los nacionalismos. Barcelona: Ariel.

Guibernau, M. (2013). Secessionism in Catalonia: After Democracy. Ethnopolitics, 12(4), 368-393. https://doi.org/10.1080/17449057.2013.843245

Hastings, A. (2000). La construcción de las nacionalidades. Etnicidad, religión y nacionalismo. Madrid: Cambridge University Press.

Hechter, M. (1976). Internal Colonialism : The Celtic Fringe in British National Development. Londres: Routledge and Kegan Paul.

Hechter, M. (2000). Nationalism and Rationality. Journal of World-Systems Research, 35(1), 308-329. https://doi.org/10.5195/jwsr.2000.226

Hechter, M. (2001). Containing Nationalism. Oxford: Oxford University Press. https://doi. org/10.1093/019924751X.001.0001 
Hobsbawm, E. (2000 [1990]). Naciones y nacionalismo desde 1790. Barcelona: Editorial crítica.

Hobsbawm, E. (2002 [1983]). La invención de la tradición. (T. Ranger, Ed.). Barcelona: Editorial crítica.

Hobson, J. (1902). Imperialism: A study. Nueva York: James Pott Company. https://doi. org/10.4324/9781912282173

Hutchinson, J. (1987). The dynamics of cultural nationalism : the Gaelic revival and the creation of the Irish nation state. Londres: Allen \& Unwin.

Hutchinson, J. (1994). Modern nationalism. Londres: Fontana Press.

Keating, M. (1996). Naciones contra el Estado. El nacionalismo de Cataluña, Quebec y Escocia. Barcelona: Ariel.

Keating, M. (2008). Thirty Years of Territorial Politics. West European Politics, 31(1-2), 6081. https://doi.org/10.1080/01402380701833723

Kedourie, E. (1988 [1960]). Nacionalismo. Madrid: Centro de Estudios Políticos y Constitucionales.

Kymlicka, W. (1996). Ciudadanía Multicultural. Barcelona: Paidós Estado y Sociedad.

Lenin, V. I. (1914). El derecho de las naciones a la autodeterminación. Prosveschenie, 1-44.

Linz, J. J. (1985). De la crisis de un Estado unitario al Estado de las autonomías. En La España de las Autonomías (pp. 527-672). Instituto de Estudios de Administración Local, Ministerio de Administración Territorial.

Linz, J. J. (2008). Obras escogidas. Vol. 2: Nación, Estado y lengua. (J. R. . Montero \& T. J. Miley, Eds.). Madrid: Centro de Estudios Políticos y Constitucionales.

Lipset, S. M., \& Rokkan, S. (1967). Party Systems and Voter Alignments: Cross-National Perspectives. New York: The Free Press.

Luxemburgo, R. (1976). The national question: selected writings. (H. B. Dave, Ed.). Nueva Yor: Monthly Review Press.

Marcos-Marné, H. (2015). Nacionalismo y etnicidad: marcos analíticos, aportaciones más recientes y principales puntos de encuentro. Revista de Estudios Políticos, (168), 319343. https://doi.org/10.18042/cepc/rep.168.11 
Marx, A. W. (2003). Faith in nation : exclusionary origins of nationalism. Oxford: Oxford University Press.

Mazzini, G. (2004 [1846-1847]). Pensamientos sobre la democracia en Europa y otros escritos. (I. M. Pascual Sastre, Trad.). Madrid: Tecnos.

Meinecke, F. (1970). Cosmopolitanism and the National State. Nueva Jersey: Princeton University Press. https://doi.org/10.1515/9781400872107

Michelet, J. (2005). El Pueblo. México D. F: Fondo de Cultura Económica.

Mill, J. S. (1861). Of Nationality, as Connected with Representative Government. En Considerations on Representative Government. Londres: Parker, Son y Bourn.

Mommsen, T., Strauss, D. F., Müller, F. M., \& Carlyle, T. (2010 [1871]). Letters on the War Between Germany and France. (N. Press, Ed.). Londres.

Moreno Almendral, R. (2016). Corrientes teóricas para el estudio de las naciones y el nacionalismo: críticas y alternativas al paradigma modernista. Revista de Estudios Políticos, 171(171), 225-253. https://doi.org/10.18042/cepc/rep.171.08

Moreno, L. (2008). La federalización de España : poder político y territorio. Salamanca: Siglo Veintiuno de España Editores.

Moreno, L., \& Lecours, A. (2009). Nacionalismo y democracia: dicotomías, complementariedades, oposiciones. Madrid: Centro de Estudios Políticos y Constitucionales.

Muñoz, J., \& Tormos, R. (2015). Economic expectations and support for secession in Catalonia: Between causality and rationalization. European Political Science Review, 7(2), 315-341. https://doi.org/10.1017/S1755773914000174

Nairn, T. (1990). The modern Janus: nationalism in the modern world. London: Hutchinson.

Núñez Seixas, Xosé Manuel. 2019. Patriotas transnacionales: Ensayos sobre nacionalismos y transferencias culturales en la Europa del siglo xx. Madrid: Cátedra.

O’Brian, C. C. (1988). God land: reflections on religion and nationalism. Cambridge: Harvard University Press.

Pérez-Nievas, S., \& Bonet, E. (2006). Identidades regionales y reivindicación de autogobierno el etnorregionalismo en el voto a partidos de Bélgica, España y Reino Unido. Revista española de ciencia política, 15, 123-161. 
Renan, Ernest. 1887. Discours et conférences. Paris: Calmann Lévy.

Rivero, Á. (2011). La constitución de la nación: patriotismo y libertad individual en el nacimiento de la España liberal. Madrid: Editorial Fundación FAES.

Rivero, Á. (2016). ¿Qué es una nación? A propósito de Dioses útiles. Fundación FAES, 69-74.

Rivero, Á. (2017). Immanuel Kant y la polémica sobre el origen del nacionalismo. Revista de Estudios Políticos, (178), 71-103. https://doi.org/10.18042/cepc/rep.178.03

Roshwald, A. (2006). The endurance of nationalism : ancient roots and modern dilemmas. Cambridge: Cambridge University Press.

Schnapper, D. (2001). La comunidad de los ciudadanos: acerca de la idea moderna de nación. Alianza ensayo 185. Madrid: Alianza Editorial.

Serrano, I. (2013). Just a Matter of Identity? Support for Independence in Catalonia. Regional \& Federal Studies, 23(5), 523-545. https://doi.org/10.1080/13597566.2013.775945

Seton-Watson, H. (1977). Nations and states: an enquiry into the origins of nations and the politics of nationalism. Londres: Westview Press.

Shils, E. (1957). Primordial, Personal, Sacred and Civil Ties. The British Journal of Sociology, 8(2), 130. https://doi.org/10.2307/587365

Smith, A. D. (1996). Opening statement Nations and their pasts. Nations and Nationalism, 2(3), 358-365. https://doi.org/10.1111/j.1469-8219.1996.tb00002.x

Smith, A. D. (1997). Identidad nacional. Madrid: Trama Editorial.

Smith, A. D. (2000). Nacionalismo y modernidad. Madrid: Ediciones Istmo.

Smith, A. D. (2004). Nacionalismo: teoría, ideología, historia. Madrid: Alianza Editorial.

Stepan, A. C. (2001). Arguing Comparative Politics. Arguing Comparative Politics. Norfolk: Oxford University Press.

Taguieff, P.-A., \& Delannoi, G. (1993). Teorías del nacionalismo. Barcelona: Paidós.

Van den Berghe, P. L. (1978). Race and ethnicity: A sociobiological perspective. Ethnic and Racial Studies, 1(4), 401-411. https://doi.org/10.1080/01419870.1978.9993241 
Sobre las teorías de la nación | Javier Antón Merino

Varouxakis, G. (2002). Mill on nationality. (M. Moran, Ed.). Londres y Nueva York: Routledge.

Von Treitschke, H. (1916). Politics (Vol. I). Nueva York: Macmillan.

Weber, M. (1948). From Max Weber : essays in sociology. (H. Gerth \& W. Mills, Eds.). Londres: Routledge y Kegan Paul.

Weber, M. (1968). Economy and Society. (Vol. 3). New York: Bedminster Press. https://doi. org/10.2307/2091965 